\title{
Um tipo diferente de diferença na elite política: perfis políticos e inserções culturais de parlamentares brasileiras*
}

\author{
Eliana Tavares dos Reis**
}

\begin{abstract}
Resumo
$\mathrm{O}$ artigo analisa perfis e inserções de oito parlamentares brasileiras que se notabilizaram tanto na ocupação de posições políticas (administrativas e eletivas) como em meios culturais (universidades, institutos, meios midiáticos, entre outros). A questão mais geral que se coloca é quem são essas mulheres, quais os recursos mobilizam e em que condições conseguem se alocar num espaço no qual são tão raras? Triplamente raras, porque se distinguem da maioria das mulheres ao entrar na competição política; dos outros políticos por serem mulheres; e da maioria dos políticos, homens e mulheres, por ocuparem o topo da hierarquia política e se destacarem, entre os profissionais da política, como produtoras de bens culturais.
\end{abstract}

Palavras-chave: Elites, Mulheres, Política e Intelectuais.

\footnotetext{
* Recebido para publicação em 9 de novembro de 2013, aceito em 8 de maio de 2014.

** Professora Adjunta do Departamento de Sociologia e Antropologia e do Programa de Pós-graduação em Ciências Sociais da Universidade Federal do Maranhão.eliana1reis@terra.com.br
} 
234 Um tipo diferente de diferença na elite política

A Different Kind of Difference in the Political Elite: Political Profiles and Cultural Insertion of Brazilian Female Legislators

\begin{abstract}
The article analyzes the profiles and insertions of eight Brazilian female legislators who are noteworthy both in occupying political positions (administrative and elective) and in the general cultural media (universities, institutes, the media itself, among others). The question that arises is who are these women, which resources do they mobilize and under what conditions do they manage to become part of a space where they are so rare? Triply rare, because they're distinguished from most women when they enter the political arena, from other politicians for being women, and from the majority of politicians -men and women - for occupying the top of the political hierarchy and standing out among political professionals as producers of cultural goods.
\end{abstract}

Key Words: Elites, Women, Politics and Intellectuals. 
A discussão que segue se inscreve no campo de estudos sobre elites políticas e culturais, centrando a análise em um universo constituído de parlamentares brasileiras que se notabilizaram tanto na ocupação de posições políticas (administrativas e eletivas) como em meios culturais (universidades, institutos, meios midiáticos, entre outros). Trata-se, especificamente, de oito mulheres identificadas em um conjunto mais amplo de agentes (deputados e senadores) situados no topo da hierarquia política e que combinam carreiras eletivas longevas com significativa produção escrita. ${ }^{1}$ A raridade de parlamentares do sexo feminino suscita indagar sobre quais são os perfis $e$ os investimentos sociais, políticos e culturais dessas empreendedoras políticas?

Mais precisamente, elas fazem parte de um universo constituído de 299 agentes, representando aproximadamente 2\% frente a uma maioria de $98 \%$ de homens que se enquadram no mesmo perfil. No estudo anterior (Grill \& Reis, 2012), esse recorte de gênero apareceu como um dado residual e a baixa frequência de mulheres poderia levar a simplesmente negligenciar essa presença ou a questionar sua relevância. No entanto, a questão que se coloca é justamente a de procurar saber quem são elas, quais recursos mobilizam e em que condições conseguem se alocar em um espaço no qual são tão raras ? $^{2}$ Triplamente raras, porque se

1 A pesquisa sobre "políticos que escrevem" mapeou inicialmente 1.181 casos de agentes que seguiram percursos políticos e também publicaram textos; posteriormente, foram delimitados 299 casos singularizados por um investimento significativo, equilibrado e relativamente sistemático na ocupação de postos políticos e produção escrita. Para esses foram aplicadas correlações entre variáveis sociográficas e os gêneros de escrita privilegiados. Ver Grill \& Reis (2012).

2 É uma justificativa semelhante àquela utilizada por Ana Paula Simioni (2008) no seu estudo sobre pintoras e escultoras acadêmicas brasileiras entre o final do século XIX e início do século XX. Depois de discutir a escassez de registros sobre as mulheres artistas do período e suas produções - lembrando a orientação de Michelle Perrot (1995) de que o empenho em realizar uma "história das mulheres" significa questionar as seleções oficiais de eventos, sujeitos e fontes tomados como universais - Simioni declara que os cinco casos que privilegiou para a análise em função da existência mais significativa de informações são exemplares justamente porque "o simples fato de que elas tenham se feito 
distinguem da maioria das mulheres ao entrar na competição política; dos outros políticos por serem mulheres; e da maioria dos políticos (homens e mulheres) por chegarem ao cume da pirâmide política e se destacarem, entre os profissionais da política, como produtoras de bens culturais.

Assim, visando melhor qualificar a investigação dos condicionantes de processos amalgamados de representação política e de formulação de bens culturais, o primeiro e mais geral eixo desta reflexão, refere-se às lógicas de reprodução e de subversão da dominação masculina, traduzidas em posições ocupadas e posicionamentos assumidos no jogo político. $\mathrm{O}$ segundo eixo diz respeito às características concentradas por profissionais da política que participam também de lutas simbólicas pela definição e pela elucidação de problemas sociais que ajudam a edificar.

Para tanto, são examinados dados de propriedades sociais, investimentos $e$ inserções políticas e culturais ao longo das biografias específicas das parlamentares, sendo que alguns deles são cotejados com regularidades verificadas para o universo dos 299 agentes, objetivando identificar possíveis particularidades ou invariâncias dos trunfos acumulados e sua reconversão em posições políticas conquistadas. $\mathrm{E}$, por esse intermédio, pretendese extrair indicadores do funcionamento de um jogo pautado por exigências de ajustes a princípios dominantes e a códigos de sucesso político (um espaço de interdições), bem como por possibilidades de criação e de inventividade que podem gerar efeitos sobre critérios sociais e políticos de excelência (um espaço de expressões).

\section{Perfis social, político e intelectual de parlamentares brasileiras}

No bojo de uma sociologia política e histórica, vários estudos têm refletido sobre processos de reconfiguração das 
formas de ação/intervenção no mundo social, sublinhando, em uma direção, a crescente diversificação de papeis, espaços, formas de mobilização e exigências de especialização dos agentes sociais (individuais e coletivos). $\mathrm{E}$, em outra direção, a competição existente entre aqueles que, em dadas circunstâncias, afirmam-se como os mais aptos ao exercício de atividades intelectuais $e$ profissionalizadas, incluindo, especialmente, a da representação política (Grill, 2013; Achin, 2001; Marenco dos Santos, 2000; Gaxie, 1992; Collovald, 1985; entre outros). Há, igualmente, uma riqueza imensurável de estudos que tratam prioritariamente seja de temáticas relacionadas às conexões entre os intelectuais $e$ a política (Coradini e Reis, 2012; Sigal, 2012; Medvetz, 1990; Pécaut, 1990; Charle, 1990; Velloso, 1987; Miceli, 1979; entre outros), seja de múltiplas formas de relacionar política e questões de gênero (Pinto, 2010, 2001; Araújo, 2009, 2005; Barreira, 2006; Dolan, 2004; Grossi e Miguel, 2001; Avelar, 2001; Souza Lobo, 1991; entre outras).

É certamente inviável inventariar com fôlego razoável a produção acadêmica em todas essas direções, com seus múltiplos objetos específicos, vertentes teóricas e universos empíricos. Para o momento, é possível estabelecer as três diretrizes analíticas derivadas do acúmulo de conhecimentos produzidos e pertinentes à reflexão da tripla intersecção temática proposta neste artigo ("política" - "cultura"- "mulher").

A primeira e mais ampla diretriz parte da existência de interpenetrações entre domínios políticos e culturais, direcionando o olhar para aquilo que se joga nas fronteiras entre universos sociais, particularmente no que diz respeito ao peso de trunfos tidos como intelectuais na conquista de reconhecimentos $e$ de posições relativamente bem situadas na hierarquia do mundo político. Conjugada a isso, a segunda prioriza os condicionantes que agem na afirmação de agentes como representantes políticos e, de maneira mais ou menos indissociável, como produtores legítimos de representações sobre a política. E a terceira diretriz desvela processos interconectados de investidura de agentes como porta-vozes autorizados e como formuladores de bens culturais, fornecendo representações sobre 
o mundo social, a partir de um universo constituído por mulheres que singularizaram suas trajetórias por esse duplo investimento (entre outros, evidentemente).

Os dados que seguem, então, foram organizados para contemplar os três eixos de análise, quais sejam, os perfis sociais, culturais e políticos das oito parlamentares investigadas. $\mathrm{O}$ exercício aqui consiste em explorar as informações biográficas das agentes e compará-las sistematicamente com as da população tratada precedentemente.

Na primeira pesquisa (centrada nos 299 casos), observou-se, por exemplo, que além de predominantemente homens, os agentes, majoritariamente, nasceram e atuam nos principais estados do país; são oriundos das chamadas "famílias de políticos" bem situadas socialmente; possuem títulos escolares e profissionais historicamente valorizados e consoantes ao exercício de papeis políticos $e$ intelectuais; $e$ adquiriram seus diplomas nas mais reputadas instituições de ensino superior (Grill \& Reis, 2012). Assim, no que as propriedades específicas das mulheres em foco se aproximam ou se distanciam dessas características dominantes?

\section{Das características sociais}

Tomando como fontes principais o Dicionário Histórico Biográfico Brasileiro (CPDOC) e os Dicionários Biográficos da Câmara dos Deputados e do Senado, as informações sobre ocupação do pai, formação escolar e profissão declarada indicam características gerais da composição social das parlamentares estudadas, relativamente ao perfil do conjunto de parlamentares tratados anteriormente.

Em primeiro lugar, no que diz respeito à ocupação do pai, atenta-se para a predominância de posições que indicam origens relativamente altas (afora uma parlamentar que é filha de um pedreiro/lavador de carros).

Em segundo lugar, a maioria realizou cursos em áreas das ciências humanas e sociais - sendo que uma delas concluiu também o curso de direito (além da formação em letras) -, 
excetuando-se três agentes que se formaram em economia, matemática e psicologia. Distinguem-se, pois, do universo mais amplo para o qual a formação em direito é a mais frequente (170/299), seguida por medicina e economia (30 e 28, respectivamente), estando as ciências humanas (21/299) e o curso de engenharia (24/299) em quarta e quinta posições (sendo que este último não se encontra representado entre as mulheres, indicando $\mathrm{o}$ persistente monopólio masculino nesse título/profissão). ${ }^{3}$

As parlamentares formadas em economia, matemática $e$ psicologia, adicionando uma quarta formada em pedagogia, história, geografia, realizaram pós-graduações em instituições de ensino estrangeiras, sendo três nos EUA e uma na França. Entre as quatro, duas também passaram pela mesma instituição de ensino prestigiada (USP) e uma (das ciências humanas) formou-se por uma universidade federal (UFPE). De um modo geral, as Instituições de Ensino Superior (IES) que frequentaram são bem alocadas no espaço escolar brasileiro, ainda que nem todas liderem a hierarquia dessas instituições. Confrontando com a distribuição em IES para o universo mais amplo, tendo em vista os estados onde estão localizadas, tem-se que entre as dez mais recorrentes estão, nas três primeiras posições, em ordem decrescente, a Universidade Federal do Rio de Janeiro (UFRJ), a Universidade Federal de Pernambuco (UFPE) e a Universidade de São Paulo (USP); em sexto e décimo lugares, respectivamente, encontram-se a Universidade Federal do Rio Grande do Sul (UFRGS) e a Universidade Federal do Pará (UFPA). Quanto ao universo das oito mulheres, tem-se um caso com formação no Rio

3 Seria relevante uma reflexão mais sistemática (o que não está entre os propósitos deste artigo) sobre como o universo escolar e as escolhas implicadas atualizam gostos e habilidades presumidas. Distinções geradas em longos processos de substancialização que abrangem formas de socialização em diferentes níveis de dicotomização do "feminino" e do "masculino" e daquilo que lhe seria "próprio": exercício de papeis, percepções, relação com os corpos e com os afetos, registros morais, preferências manifestas (esportes, tarefas domésticas, sensibilidades, etc.), entre outros que estão na base de disposições para, por exemplo, certas matérias e cursos escolares. 
Janeiro, porém pela Universidade Estadual (UERJ); uma na UFPE; duas parlamentares realizaram cursos na USP; outras duas frequentaram instituições privadas em São Paulo - Mackenzie e Pontifícia Universidade Católica (PUC/SP); a deputada titulada no Rio Grande do Sul que se formou também pela Pontifícia Universidade Católica (PUC/RS); e uma pela UFPA.

Sublinha-se o predomínio da área de humanas ou do uso dos títulos para o exercício da docência - a maioria das parlamentares (cinco) declara ser professora e todas exerceram, no decorrer dos seus itinerários, atividades de ensino variadas $-e$ a correspondência entre as profissões $e$ as formações escolares (com exceção da jornalista que realizou seus estudos universitários em filosofia).

Ainda que não seja possível afirmar uma proeminência escolar dessas agentes em relação aos demais parlamentares que compõem os 299 casos, o exame do perfil de uma delas realça um aspecto que deve ser grifado. Trata-se daquela com origem social mais baixa, que se constitui como "mulher", "negra", "favelada", "evangélica", "petista" e que chegou à posição de senadora $e$ ministra de Estado. A escolaridade, juntamente com as adesões políticas e religiosas, certamente se coloca como trunfo importante, no mínimo potencializando as demais inscrições. ${ }^{4}$

Sobressai também, no que tange ao tipo de escolarização, a parlamentar que concluiu o curso de economia e construiu sua carreira, fundamentalmente, a partir de uma competência técnica, chegando à deputação federal, ao Ministério do Planejamento $e$ ao governo do estado do Rio Grande do Sul. É possível considerá-

4 O que leva a pensar nas considerações feitas por Baudelot e Establet (2007) de que não há uma superioridade escolar das mulheres dos estratos sociais mais abastados, enquanto o contrário acontece para as camadas médias e mais modestas, nas quais há um maior investimento escolar das meninas em relação a seus homólogos masculinos, constituindo o título em recurso significativo de distinção e ascensão social. Uma explicação para isso seria a de que o maior investimento das meninas provenientes dos meios populares em educação pode estar relacionado ao papel exercido por suas mães que, geralmente, são as responsáveis pelas contas a pagar, documentações, exercício da escrita, entre outros, e, sendo mais próximas das suas filhas, estimulam-nas a superar determinadas barreiras sociais (Lahire, 1995, apud Guionnet e Neveu, 2004). 
la como exemplar do processo, descrito por Maria Rita Loureiro (1992), em que o saber econômico se afirma como nova linguagem do poder, permitindo, aos detentores e interessados, galgar posições de destaque como dirigentes políticos.

A partir do que foi exposto, pondera-se sobre a transfiguração dos recursos escolares e sociais detidos nas inscrições culturais e políticas privilegiadas por essas mulheres.

\section{Das inscrições culturais}

As informações biográficas apontam a significativa inserção das agentes em diversos meios de produção, transmissão $e$ celebração de bens culturais. Todas exerceram, em algum momento das suas trajetórias, atividades docentes; com exceção de uma, publicaram artigos em revistas e/ou jornais; e três chegaram a atuar como apresentadoras/analistas de rádio e/ou $\mathrm{TV}$, duas delas com temas voltados para as mulheres (uma relacionando "mulher", "religião" e "família", a outra associando "mulher", "sexualidade" e "relações de poder") e uma sobre questões econômicas. Adiciona-se a isso a ocupação de lugares de destaque em instâncias de consagração intelectual (como academias ou centros de estudos) e políticas (como associações e conselhos direcionados a questões e categorias variadas: mulher, igreja, educação, sexualidade, condição social...) que atualizam as diferentes vias de articulação entre as carreiras eletivas, a condição de intelectual e o papel de porta-voz de determinadas causas e problemáticas.

Tais inserções são exemplificadas no quadro abaixo, no qual somente não há o registro de uma das oito mulheres, filha de um pastor adventista, vinculada a partidos de direita e para qual, comparativamente às demais, foi detectada a menor produção $e$ inserções culturais. 


\begin{tabular}{|c|c|c|}
\hline & Inscrições Midiáticas & Academias de letras, associações, institutos, etc. \\
\hline 1 & $\begin{array}{l}\text { Produção e apresentação de programas de TV: } \\
\text { Literatura brasileira na TV (TV Excelsior, 1960- } \\
\text { 1961); ABC para você (Rádio Record, 1961- } \\
\text { 1963); O Mundo é das mulheres (TV Globo). } \\
\text { Cronista política do rádio/TV: Crônica da } \\
\text { Cidade (Rádio Record, 1963); Política com p } \\
\text { maiúsculo (TV Tupi, 1963-1964). }\end{array}$ & $\begin{array}{l}\text { Academia Cristã de Letras; Federação dos } \\
\text { Museus; Associação dos Jornalistas e Escritores } \\
\text { do Brasil; União Cívica Feminina; Associação } \\
\text { Cristã Feminina; Conselho da Mulher } \\
\text { Empresária da Associação Comercial de SP; } \\
\text { Associação das Mulheres de Negócio e } \\
\text { Profissionais de São Paulo. }\end{array}$ \\
\hline 2 & $\begin{array}{l}\text { Autora de artigos semanais sobre educação } \\
\text { publicados no Jornal de Brasília, 1980-1982. }\end{array}$ & $\begin{array}{l}\text { Membro da Academia de Letras e Música do } \\
\text { Brasil; fundadora da Sociedade Interam. de } \\
\text { Adm. da Educação (1982); membro da Assoc. } \\
\text { Nacional dos Professores em Adm. Educacional } \\
\text { (DF) e da Inter Comparative Educational } \\
\text { Society, na Pensilvânia (EUA, 1990). }\end{array}$ \\
\hline 3 & $\begin{array}{l}\text { Analista para Assuntos Econômicos da Rede } \\
\text { Brasil Sul de Rádio e Televisão (RBS), Porto } \\
\text { Alegre/RS (1988-1992); Articulista do jornal } \\
\text { Zero Hora, Porto Alegre (desde 1988); } \\
\text { Articulista do jornal Folha de S. Paulo, Porto } \\
\text { Alegre e São Paulo (1988-1989); Articulista do } \\
\text { jornal Correio do Povo, Porto Alegre (1986- } \\
\text { 1988); Analista para Assuntos Econômicos da } \\
\text { empresa Caldas Junior - Rádio e TV Guaíba e } \\
\text { jornal Correio do Povo, Porto Alegre (1981- } \\
\text { 1988). }\end{array}$ & $\begin{array}{l}\text { Diretora de Estudos e Pesquisas do Instituto } \\
\text { Teotônio Vilela (1999). }\end{array}$ \\
\hline 4 & $\begin{array}{l}\text { Artigos para o Jornal Zero Hora de Porto } \\
\text { Alegre. }\end{array}$ & $\begin{array}{l}\text { Fundadora, professora e coordenadora do } \\
\text { Grupo de Estudos sobre Educação, } \\
\text { Metodologia de Pesquisa e Ação (déc. 1970). }\end{array}$ \\
\hline 5 & $\begin{array}{l}\text { Publica artigos variados em diferentes jornais de } \\
\text { circulação nacional e periódicos. }\end{array}$ & $\begin{array}{l}\text { Fundadora do departamento feminino da } \\
\text { Federação das Associações de Favelas do } \\
\text { Estado do Rio de Janeiro (Faferj) e do Centro } \\
\text { de Mulheres de Favelas e Periferia (Cemuf). }\end{array}$ \\
\hline 6 & $\begin{array}{l}\text { Programa diário de televisão "TV Mulher", na } \\
\text { Rede Globo (década de 1980); participante } \\
\text { diária, Programa Comportamento Sexual, TV } \\
\text { Manchete; artigos em revistas e jornais como O } \\
\text { Globo, Jornal do Brasil e Folha de S. Paulo, } \\
\text { sobre políticas públicas de saúde, educação e } \\
\text { trabalho, dentro da perspectiva de gênero. }\end{array}$ & $\begin{array}{l}\text { Fundadora e presidente de honra do Grupo de } \\
\text { Trabalho e Pesquisa em Orientação Sexual. } \\
\text { Membro da Sociedade Brasileira de Psicanálise; da } \\
\text { International Psychoanalytical Association; } \\
\text { fundadora e ex-presidente do Instituto de Políticas } \\
\text { Públicas Florestan Fernandes (1999-2000); } \\
\text { Fundadora e presidente do Grupo TVer (1970). }\end{array}$ \\
\hline 7 & $\begin{array}{l}\text { Jornal do Comércio; Diário de Pernambuco; } \\
\text { Visão Editorial (1973-1975); J. Câmara Irmãos } \\
\text { (1975-1976). }\end{array}$ & $\begin{array}{l}\text { Fundadora do Centro de Estudos Políticos e } \\
\text { Sociais Teotônio Vilela (1983); presidente da } \\
\text { seção regional do Instituto Alberto Pasqualini } \\
\text { em Pernambuco, organismo de estudos } \\
\text { políticos ligado ao PDT (1991). }\end{array}$ \\
\hline
\end{tabular}


Aos aspectos referentes às inscrições culturais das parlamentares, adicionam-se aqueles concernentes ao tipo de produção escrita privilegiado por elas. Sem considerar a infinidade de artigos em jornais e revistas de grande circulação (que é o formato mais frequente das publicações), de um modo geral foi localizado um montante de 107 títulos, com uma média de 13 textos (preponderantemente livros) publicados por agente.

Considerando amplamente a classificação dos tipos de escrita e temática, bem como as correlações realizadas na pesquisa abrangendo os 299 parlamentares, há nítidas aproximações com as regularidades evidenciadas para o universo mais restrito. Nomeadamente, obtiveram-se entre os tipos de escrita mais recorrentes aqueles que exigem conhecimentos especializados, 124 (41,5\%), e os de caráter generalista, 98 (32\%); seguidas das chamadas biografias históricas (centradas na exaltação, particularmente, de contextos, eventos ou personagens), 52 (17,5\%); a dedicação à literatura (romances, poemas...) foi constatada para $23(7,5 \%)$ casos; e somente $2(0,7 \%)$ dos agentes se dedicaram à produção de memórias ou algum tipo de relato autobiográfico. ${ }^{5}$

É possível identificar entre as mulheres parlamentares a consagração de registros de escrita em proporções próximas às apresentadas acima. Ou seja, prevalecem as publicações de caráter mais especializado e generalista, que aumentam em importância nas últimas décadas. Também há a associação, aparentemente elementar, entre escritos generalistas e a formação em áreas de humanidades (letras, magistério, serviço social), e entre escritos especializados com títulos em áreas mais técnicas (como economia, direito e até psicologia).

\section{Das posições políticas}

A inserção das mulheres na esfera política institucionalizada é problematizada em numerosos trabalhos que visam entender divisões de gênero e seus condicionantes nas arenas política,

${ }^{5}$ A classificação utilizada foi inspirada no trabalho de Le Bart (1998). 
partidária e eleitoral (Araújo, 2009, 2005; Pinto, 2001; Barreira, 2006; Grossi e Miguel, 2001; Souza Lobo, 1991; Avelar, 2001; entre outro/as).

Cabe assinalar desde já que não está entre os propósitos desta análise discutir a necessidade de participação mais significativa, do ponto de vista quantitativo, das mulheres na política institucional e eletiva ou mesmo ceder a uma "síndrome positiva da exclusão" que leva a considerar aquilo que é "numericamente inferior no campo da política, em qualitativamente superior" (Barreira, 2006:4). Nem tampouco se pretende aclamar características e conteúdos como propriamente "femininos" ou naturalmente necessários ao espaço do poder (para "humanizá-lo", por exemplo), ou pressupor a existência de uma categoria como provida de unidade social, homogênea, reificada, logo, desconsiderando a heterogeneidade dos seus usos possíveis em dinâmicas de luta. Seria arbitrário reivindicar uma espécie de "feminização" do jogo político, o que implicaria em comprovar, como indicaram Lévêque e Dulong (2002), a existência de práticas políticas especificamente (ou "naturalmente") femininas e que sejam mais ou menos "hegemônicas".

Aparentemente positivadoras da atuação política das mulheres, tais posturas, quando atribuídas "de fora" (por pesquisadores ou pares que não se constituem "como parte"), podem assumir ares de solicitações condescendentes de uma presença essencializada e essencializadora de interesses, consoantes à "autoevidência" da "desigualdade" de uma "minoria". 6 No entanto, quando solicitadas "por dentro", podem trazer à tona como determinadas características, concebidas como signos de exclusão, são passíveis de serem acionadas na competição política. Ou seja, aquilo que constitui o "ser mulher" pode aparecer como um handicap justamente para obtenção de proveitos retirados da composição de certas propriedades de gênero. É preciso, pois, ponderar sobre as possibilidades de

\footnotetext{
6 Lógica aplicada a categorias como "gênero", "raça" e "classe", não raro, como apontou Scott (1995:73), sugerindo equivocadamente a existência de uma paridade entre elas.
} 
investimentos no sentido de transformar elementos de exclusão socialmente instituídos em atributos positivamente acionados nas relações de poder (Guionnet e Neveu, 2004).

A pretensão aqui é apenas sistematizar alguns indicadores de atuação e ocupação de cargos que possibilitam obter elementos do perfil político das parlamentares que se distinguem de outros/as parlamentares por suas inscrições em domínios culturais.

Os estados da federação nos quais as agentes atuaram encontram-se entre os seis primeiros mais frequentes para os 299 parlamentares (somam 222 casos e $75 \%$ do total): São Paulo, Rio Grande do Sul e Pernambuco (estão, respectivamente, na primeira, quinta e sexta posições no quadro geral, e com duas representantes em cada um deles no quadro específico). Há um caso no Rio de Janeiro (o segundo mais recorrente para o conjunto dos parlamentares) e um no Pará (que está entre os $25 \%$ dos demais estados na classificação mais ampla).

A idade de ingresso formal na política é, em geral, com mais de 39 anos e ocorre principalmente entre as décadas de 1970 e 1990. Destaca-se a convergência de três casos cujas entradas são anteriores em termos de idade e de décadas de estreia em cargos públicos (principalmente nos 1960), e cujos percursos de filiação a partidos são passíveis de serem classificados como "à direita", em diferentes períodos (UDN, Arena, PDS, PL, PFL, PTR, PPB, PDC e $\mathrm{PP})$; ao passo que as demais podem ser localizadas como mais "ao centro" (direita e esquerda) ou "à esquerda" no espectro de forças político-partidárias (MDB, PMDB, PSDB, PDT e PT).

Quatro delas passaram a ocupar cargos políticos (administrativos e eletivos) a partir da década de 1980 e se encontram em atividade - por isso o tempo de carreira é de três décadas. Sublinha-se que duas não possuem perspectiva de carreira, pois já faleceram; uma perdeu o mandato de deputada em 2010 e, posteriormente, a Justiça do Distrito Federal manteve sua condenação por improbidade administrativa, o que significa que não poderá concorrer a cargos públicos até 2020; e outra, célebre por ter sido a primeira mulher senadora do país, em 1979, pela ARENA (foi a segunda deputada estadual mais votada 
do Amazonas, de 1974 a 1978), aposentou-se por idade em 1999, no cargo de vice-presidente do colegiado do Tribunal de Contas do Amazonas.

Considerando as sequências de cargos políticos ocupados, é possível perceber que quatro dessas parlamentares ingressaram na carreira por cargos administrativos, três por cargos eletivos e uma como assessora parlamentar; enquanto quatro chegaram, como cargo mais alto, a senadoras, três a deputadas federais e uma a governadora. No que tange aos cargos administrativos, sete alcançaram a direção de ministérios ou secretarias, sendo três na área da educação, duas da cultura, uma da igualdade racial (ministra) e uma do planejamento (ministra pertencente ao PSDB, formada em economia com pós-graduação, e com uma carreira em que prepondera o perfil administrativo). A única que não ocupou tais postos no executivo foi a jornalista, que ingressou como assessora e faleceu precocemente em 1992.

Acentua-se que os trajetos não parecem diretamente ligados aos dados de ingresso (década ou idade) ou ao perfil ideológico/partidário. Ao contrário, a ascensão a cargos elevados e a superação de bloqueios parecem decorrentes de atributos pessoais $e$ identificações pessoalmente construídas nos percursos em instâncias variadas como a mídia, a religião, o magistério, os movimentos sociais, etc. Não deixando de mencionar a primazia de mulheres em cargos situados no polo dominado (a chamada mão esquerda do Estado) das lutas palacianas (Bourdieu, 1989), já bastante ressaltada na bibliografia sobre mulheres na política.

Três das agentes, com perfis sociais e políticos bastante heterogêneos, atuaram como constituintes vinculadas aos seguintes partidos: ARENA, PT e PSDB/PDT. De 590 parlamentares, 26 mulheres participaram como deputadas (nenhuma senadora) da Assembleia Nacional Constituinte de 1988 (Sow, 2010). ${ }^{7}$ Para os propósitos do argumento aqui desenvolvido, destaca-se as

\footnotetext{
7 Além da produção da "Carta das Mulheres Brasileiras aos Constituintes", tiveram uma comissão para discutir os seus direitos: a Comissão da Soberania e dos Direitos e Garantias do Homem e da Mulher.
} 
áreas de atuação das três parlamentares em pauta: menor, creche, planejamento familiar, licença maternidade e família; planejamento familiar, menor, educação, trabalho doméstico, igualdade de sexo, licença gestante; planejamento familiar, educação, menor, aborto e família. No entanto, distinguiram-se nas subcomissões às quais se vincularam - compatíveis com os perfis e temáticas/causas por elas mais diretamente priorizadas -, por exemplo: Subcomissão da Família, do Menor e do Idoso; Subcomissão dos Negros, Populações Indígenas, Deficientes e Minorias; Subcomissão da Ciência e Tecnologia e da Comunicação (Sow, 2010).

Conjugam-se aos cargos políticos anteriores (foram vereadoras, deputadas estaduais e deputadas federais), as vicelideranças e vice-presidências. Foram vice-líder do governo, vicelíder do partido, vice-líder do bloco partidário pertencente; vicepresidente do diretório regional do partido, vice-presidente do senado federal, entre outros. Sendo assim, ainda que exerçam mandatos nacionais, raramente acumulam posições de primeira liderança, mesmo que detenham recursos social e politicamente valorizados (proveniência de meios sociais privilegiados, escolarização, inserções e redes políticas, etc.).

Irlys Barreira (2006:16-17) ponderou que a participação de deputadas e senadoras, comumente em comissões de educação $e$ cultura e seguridade social e família, não necessariamente significa o reflexo de uma "divisão hierárquica do trabalho político", mas, provavelmente, a busca das parlamentares em coadunar suas formações, profissões, militâncias, inserções prévias às temáticas privilegiadas. É na ocupação de certos postos como de direção das Mesas ou funções de liderança que se pode evidenciar a desigual distribuição de posições dominantes. Logo, verificando-se na seleção a esses lugares de liderança a dinâmica mais evidente de estratégias de defesa institucional e de reprodução dos representantes do sexo masculino. 


\section{Biografias e construções de equivalências}

A conquista de posições políticas por mulheres, bem como os sentidos e impactos que encerram, estão relacionados a espaços de possíveis (Bourdieu, 1996) delineados em sucessivas configurações históricas e sociais (Lagrave, 1990). São comumente ressaltadas as transformações no âmbito político (a atuação de grupos feministas articulados sob condições restritivas impostas pelo regime militar nos anos 1970, ou as lutas em torno do sistema de cotas, inscritas no debate mais abrangente sobre a eficácia de ações afirmativas nos anos 1990, são exemplares); no econômico (reordenações da divisão social do trabalho, realocação de tarefas e redefinições de "competências"); e no cultural (investimentos em escolarização, diversificação das universidades, dos cursos universitários, do mercado editorial, dos princípios de produção de bens culturais variados, e a própria produção de conhecimento científico).

As agentes aqui tratadas estão localizadas em diferentes estágios de processos de emergência, afirmação e disputas em torno das "causas" e das próprias porta-vozes das mulheres. Examinando-se as biografias, têm-se pistas da inserção das parlamentares no trabalho de consagração social e institucional de uma série de direitos considerados como ganhos ao reconhecimento/politização de questões relativas às mulheres. Como está sendo sustentado, é imprescindível verificar as propriedades $e$ os trunfos detidos que autorizam tomadas de posição que, não raro, se objetivam em garantias legítimas. ${ }^{8}$

Sendo assim, as anotações que seguem visam, ao mesmo tempo, retomar aspectos dos perfis sociais, culturais e políticos das agentes e relacioná-los, ainda que de modo preliminar, a equivalências que sintetizam suas principais inscrições $e$ posicionamentos (extraídos de fontes variadas, como repertórios

8 Um exemplo é a afirmação do sistema de cotas para as mulheres nos partidos políticos. Para a discussão sobre os efeitos e outros aspectos condicionantes da inscrição de mulheres na esfera política e no recrutamento dos partidos políticos, ver Araújo (2005); Grossi e Miguel (2001), entre outros. 
biográficos, entrevistas localizadas em diferentes sítios de internet, escritos das próprias parlamentares, entre outros). Mais especificamente, foram buscadas referências atinentes à participação no mundo político, especialmente relativas à ativação das categorias "mulher", "gênero" e "feminino". Dois apontamentos devem ser feitos. O primeiro de que a mobilização dessas categorias pode expressar princípios de reprodução, formas de identificação ou dispositivos estratégicos de luta (que podem emergir de forma dissociada e/ou imbricada, conforme o perfil). E o segundo de que não há uma relação imediata entre referências à condição feminina, de mulher ou de gênero e a persistência ou o combate a formas de reprodução de relações e lógicas de dominação; do mesmo modo, a ausência desses termos nas tomadas de posição não significa, diretamente, submissão $e$ entrave à busca de equilíbrio da balança de poder (Elias, 1999).

Para a descrição subsequente, propõe-se uma sequência mais ou menos lógica dos perfis pesando os desencadeamentos das biografias das agentes em termos cronológicos e de localizações no espectro político-ideológico, haja vista serem esses os condicionantes que parecem oferecer indícios distintivos das condições de entrada e de intervenção no jogo social e político.

Os três primeiros casos dizem respeito a parlamentares com formação em línguas, pedagogia e magistério, respectivamente (duas delas não investiram em pós-graduação), que estrearam sua participação no cenário público nas décadas de 1950 e 60, em partidos considerados de direita no espectro político ideológico (as três passaram pela Arena, pelo PDS e pelo PFL), e, comparativamente às demais, são aquelas com o ingresso mais precoce na política, tendo assumido o primeiro cargo antes dos 30 anos de idade (26, 28 e 29 , respectivamente):

A primeira é formada em direito (assim como seu marido, que também é médico e empresário), além de ser cantora e escritora. Participou de concertos de música de câmera $e$ folclórica internacional e cursos de história da música para a Secretaria de Educação e Cultura da Prefeitura de São 
Paulo, bem como atuou em rádio e televisão, onde produziu e apresentou diversos programas e foi cronista política de programas diários. O pai foi empresário $e$ político, do qual teria herdado a carreira política. O primeiro cargo eletivo foi como vereadora na legenda da União Democrática Nacional (UDN) e foi uma das articuladoras do movimento Marcha da Família com Deus pela Liberdade. Foi deputada estadual por São Paulo (1966-1974) e Senadora (1982). Entre outras pertenças, foi membro da Academia Cristã de Letras, da Associação dos Jornalistas e Escritores do Brasil, da União Cívica Feminina, da Associação Cristã Feminina, do Conselho da Mulher Empresária da Associação Comercial de São Paulo e da Associação das Mulheres de Negócio e Profissionais de São Paulo. A maior parte da sua produção escrita foi publicada na década de 1990 e priorizou trabalhos especializados (gramática), literatura e biografia histórica. Ela acionou nos seus posicionamentos as condições/causas de mulher, cultura, religião, de direita e empresária. Faleceu aos 83 anos, em 2008, por insuficiência cardíaca e é "considerada uma das celebridades intelectuais e políticas com berço em Rio Preto". (Principais fontes: DHBB $e$ $<$ http://www.diarioweb.com.br/editorial/corpo_noticia $>$, acessado em dezembro, 2012).

A segunda realizou também os cursos de história $e$ geografia, bem como fez pós-graduação no Rio de Janeiro e nos Estados Unidos. O primeiro cargo ocupado foi em 1965, como secretária de Educação e Cultura do governo arenista de Jarbas Passarinho, no Pará. Em 1969, assumiu o cargo de diretora do departamento de Ensino Fundamental do Ministério de Educação e Cultura (MEC), em Brasília (DF), e compôs o grupo estadual para elaboração do projeto MEC/Banco Internacional de Reconstrução e Desenvolvimento (BIRD) e a comissão encarregada de estruturar a Faculdade de Educação da UFPA. Entre outras atribuições, na década de 1970: chefiou a delegação brasileira à Conferência Especializada sobre Educação Integral da Mulher da OEA, em Buenos Aires; ingressou no Conselho Federal de Educação; viajou aos 
Estados Unidos, a convite da United States Agency for International Development (USAID - Agência NorteAmericana para o Desenvolvimento Internacional); foi membro suplente da Comissão de Moral e Civismo do Distrito Federal e Secretária de Educação e Cultura do Distrito Federal (1979-1985). O primeiro mandato, como deputada federal, veio somente no início da década de 1990 (pelo extinto Partido Trabalhista Reformador/PTR). Foi filiada ainda ao: Partido Progressista (PP), ao Partido Progressista Brasileiro (PPB) e ao Partido do Movimento Democrático Brasileiro (PMDB). Em 1999, assumiu pela quarta vez a pasta da Educação do Distrito Federal. Foi deputada distrital (2002-2006). Sua dedicação à produção escrita foi mais intensa durante a década de 1970, e contemplou, basicamente, temáticas educacionais, de um ponto de vista mais preponderantemente especializado (Principais fontes: DHBB e $<$ http://www2.camara.leg.br/deputados $>, \quad$ acessado em novembros de 2012).

A terceira tem uma origem adventista (o pai é pastor $e$ colportor-evangelista) e o primeiro cargo público foi no Serviço Municipal de Educação (1958-1962). Vinculada à ARENA, foi eleita deputada estadual, em 1974, ocupou a Secretaria do Trabalho e Ação Social do governo e chegou ao Senado em 1979 (seu principal trunfo é ter sido a primeira mulher a ocupar um lugar no Senado Federal). Com o pluripartidarismo, filiou-se ao PDS. Participou da criação do Movimento da Mulher Democrática Social (MMDS) e foi eleita deputada federal pelo PFL, em 1986. Integrou a Assembléia Nacional Constituinte (que elaborou a Constituição de 1988) nas áreas do menor, creche, planejamento familiar, licença maternidade e família. Disputou a reeleição pelo PDC em 1990, mas não obteve êxito. Foi conselheira do Tribunal de Contas do Amazonas $e$ vice-presidente do colegiado até aposentar-se por idade, em 1999. Nas suas tomadas de posição, ela articula ideias de política, família e religião, apresenta-se como defensora de direitos para mulheres e condena os preconceitos de gênero com base em "ensinamentos bíblicos". A agente 
reúne o menor número de publicações e de inserções culturais (em comparação com as demais). Seus escritos são basicamente de caráter generalista (mulher e família) e especializada (educação) (Principais fontes: DHBB; $<$ http://www2.camara.leg.br $>\quad e$ $<$ http://dialogue.adventist.org/articles/>, acessados entre novembro e dezembro de 2012).

O próximo caso se singulariza pelo engajamento militante, com a ocupação do seu primeiro mandato aos 39 anos, em um partido oposicionista. A agente morreu em 1992, vítima de um câncer de mama. Observa-se no seu perfil uma maior politização da categoria "mulher" em detrimento da associação direta com determinados papeis ou universos da vida social (como educação, família e religião), delineando, pois, um perfil que será mais recorrente nas próximas parlamentares a serem apresentadas.

Formada em línguas, sem pós-graduação, atuou como jornalista e exerceu por duas vezes o mandato como deputada federal: eleita em 1978, pelo MDB; e, em 1982, pelo PMDB, partido ao qual se filiou com $\mathrm{O}$ pluripartidarismo e do qual se tornou vice-líder. Durante a primeira legislatura, integrou a delegação de parlamentares que visitou Cuba e a delegação que participou das festividades do quarto aniversário da revolução sandinista, na Nicarágua. E, na segunda, fundou o Centro de Estudos Políticos e Sociais Teotônio Vilela. Assim como a parlamentar anteriormente descrita, foi deputada federal constituinte, eleita em 1986. Ao longo de sua atuação na Constituinte, dentre outras coisas, defendeu as principais bandeiras do movimento feminista, como a legalização do aborto, a instalação obrigatória de creches nas empresas e a ampliação dos direitos da mulher trabalhadora. Pertencente à facção considerada mais "à esquerda" do PMDB, deixou o partido em junho de 1988, para ser uma das fundadoras do Partido da Social Democracia Brasileira (PSDB). Logo em seguida, no entanto, filiou-se ao PDT e, sem sucesso, tentou a reeleição em 1990. Deixou a Câmara dos Deputados em janeiro de 1991, ao final da legislatura. 
Passou a presidir a seção regional do Instituto Alberto Pasqualini em Pernambuco, instância de estudos políticos ligado ao PDT. Seus escritos, concentrados na década de 1980, articularam questões clássicas da esquerda constituída nos processos de luta contra a ditadura e redemocratização do país, bem como se enquadram num registro mais generalista e memorialístico. Em homenagem póstuma, foi definida como uma mulher "aguerrida", "ousada", "forte", "coerente", "passional", "corajosa", "inteligente", "racional". Seu nome foi dado a um instituto de combate ao câncer (Principais fontes: DHBB; <http://www.onordeste.com/>; $<$ http://www.vecgaranhuns.com/ $>$, acessados em fevereiro de 2013).

Em comum com as duas anteriores, a parlamentar agora em questão foi Constituinte e, a exemplo da última, aciona, entre as principais clivagens sociais que marcam a sua militância, o discurso "classista". Mais especificamente o relacionado à distinção fundada em uma origem social baixa (nas favelas do Rio de Janeiro), juntamente com o fato de ser negra.

Filha de um pedreiro/lavador de carros, ela começou a trabalhar na infância $e$, entre outras atividades, foi empregada doméstica, professora de uma escola comunitária e funcionária do Departamento Estadual de Trânsito (DETRAN), no RJ. Em 1972, converteu-se à religião evangélica; em 1976, foi presidente da Associação de Moradores do Morro do Chapéu Mangueira. Foi fundadora do departamento feminino da Federação das Associações de Favelas do Estado do Rio de Janeiro (FAFERJ) e do Centro de Mulheres de Favelas e Periferia (CEMUF). Trabalhou com políticos do Movimento Democrático Brasileiro (MDB); e, na década de 1980, participou da fundação do PT, elegeu-se vereadora, formou-se pela Faculdade de Serviço Social do Rio de Janeiro, e elegeu-se deputada federal na legenda do PT, (enquanto seu então marido, liderança comunitária, concorria, sem êxito, a vicegovernador do estado do Rio de Janeiro na chapa encabeçada pelo escritor e jornalista Fernando Gabeira). Reelegeu-se em 1990. Nessa década, concorreu, sem 
sucesso, à prefeitura do Rio de Janeiro; foi titular da Comissão de Relações Exteriores da Câmara dos Deputados e defendeu a aproximação comercial e cultural do Brasil com os países africanos; foi empossada Senadora, participou da IV Conferência Mundial da Mulher (Pequim); conseguiu a aprovação do Senado à sua emenda constitucional regulamentando o trabalho dos empregados domésticos e estendendo à categoria benefícios trabalhistas. Foi vice-governadora do estado do Rio de Janeiro, eleita em 1998, e governadora interina, em 2002 (em razão da renúncia do titular para concorrer à Presidência da República). Em 2003, foi Secretária Especial da Assistência e Promoção Social da Presidência da República, com status ministerial. Não raro, a agente constrói equivalências em torno das condições de mulher, negra e pobre, sublinhando suas inscrições militantes em questões derivadas desse trinômio, de sua identificação religiosa (evangélica) $e$ política (ao PT). Atualmente, é casada com um ator e sua produção tem um caráter mais frequentemente generalista $e$ está publicada no âmbito da Câmara dos Deputados ou do Senado Federal (Principais fontes: DHBB; $<$ http://www2.camara.leg.br/>; <www.senado.leg.br $>$, acessados em fevereiro de 2013).

Há ainda casos que, assim como a antecedente, ilustram perfis de militantes de esquerda, no entanto com origens econômicas mais abastadas. Para essas agentes, as intervenções política e cultural são diretamente relacionadas, respectivamente, a questões de educação e gênero, a partir das suas especialidades de formação e atuação profissional.

A primeira é filha de um pecuarista e tropeiro, casada com um pediatra, ela cursou matemática e investiu fortemente na formação em pós-graduação na França. Professora e pesquisadora, em 1970, ela foi uma das fundadoras do Grupo de Estudos sobre Educação, Metodologia de Pesquisa e Ação (GEEMPA), voltando-se ao ensino em escolas públicas e a potencialização do rendimento escolar de alunos de origens sociais mais humildes. Foi candidata, 
no início dos anos 1980, à vice-presidência do sindicato de professores do Rio Grande do Sul (CPERS). A carreira política institucional foi inaugurada em 1989, como secretária municipal de educação de Porto Alegre, na primeira gestão do $\mathrm{PT}$ (de uma sequência de quatro mandatos petistas) à frente daquela prefeitura. Pelo mesmo partido foi deputada federal de 1995 a 2002, falando basicamente em nome da educação. A partir das ONGs GEEMPA e THEMIS (esta última fundada em 1993 e dedicada a Assessoria Jurídica e Estudos de Gênero) a agente é responsável pelo projeto, desenvolvido desde 2002, que visa a alfabetização de mulheres das classes populares em três meses, financiado pela UNESCO e pela UNICEF. Sua produção combina as discussões especializadas e generalistas, principalmente na década de 1990, bem como prioriza a articulação entre formulações acerca das categorias "educação" e "gênero" com a prática política voltada à politização de ambas (Principais fontes: DHBB;

$<$ http://www.geempa.org.br/>). $<$ http://www2.camara.leg.br/>;

A segunda é filha de uma família da elite paulistana (o pai fora um grande industrial). A parlamentar nasceu em 1945. Seu primeiro casamento foi em 1964, com um economista, professor universitário, industriário, senador pelo mesmo partido da parlamentar e igualmente proveniente de uma família paulistana tradicional (se separou dele em 2001). Concluiu o curso de psicologia (PUC/SP) em 1975 e realizou mestrado na mesma área na Universidade de Michigan. Atuou como professora e terapeuta entre 1973 e 1976. Na década de 1980, apresentou diariamente o quadro "Comportamento sexual" no programa TV Mulher (TV Globo e TV Manchete). Em 1981, filiou-se ao PT e, durante a administração de Luiza Erundina na prefeitura de São Paulo, foi responsável pela elaboração e pela implantação do programa de orientação sexual nas escolas do município (o educador Paulo Freire respondia pela Secretaria Municipal de Educação). Depois de inserções em movimentos feministas $e$ vinculados a questões de sexualidade, elegeu-se deputada federal, em 1994. 
Posicionou-se sobre: a reestruturação do Conselho Nacional dos Direitos da Mulher; a descaracterização do adultério como crime; assédio sexual; a descriminalização do uso da maconha; aprovação de projeto para permitir o aborto quando se constatasse a anomalia do feto; a união civil entre pessoas do mesmo sexo. Destacou-se na aprovação do projeto de sua autoria garantindo a reserva para as mulheres de $20 \%$ das vagas de candidatos de cada partido, coligação etc. Disputou, sem sucesso, a eleição para o governo de São Paulo, em 1998; e, em 2000, concorreu, com êxito, à prefeitura da mesma cidade. Casou-se novamente em 2003, com um publicitário, membro da Secretaria de Relações Internacionais do PT. Não conseguiu se reeleger na campanha eleitoral de 2004. Em 2007, durante o governo do Presidente Luiz Inácio Lula da Silva, assumiu o Ministério do Turismo. Em 2010, elegeu-se senadora e, em 2012, foi nomeada Ministra da Cultura pela Presidente Dilma Rousseff. A vasta produção escrita é distribuída entre discussões generalistas $e$ especializadas na área de sexologia (Principal fonte: Dicionário Histórico e Biográfico Brasileiro).

Todavia, entre as agentes estudadas, ingressantes na arena política nas últimas décadas, há um caso cuja base de legitimação se apoia prioritariamente na formação acadêmica e na especialização profissional em um domínio de saber que vem se tornando hegemônico: a economia.

Filha de um diretor de um grande laboratório farmacêutico (ele é mencionado como representante comercial de uma multinacional e também como contabilista e jornalista), a agente nasceu na cidade de São Paulo, em 1944. Começou a trabalhar com 16 anos e foi estagiária da Secretaria da Fazenda e funcionária do Tribunal de Contas, enquanto cursava economia na USP (1963). Em 1967, atuou como economista na Federação do Comércio do Estado de São Paulo, transferindo-se no ano seguinte para a Viação Aérea São Paulo (VASP). Em 1968, concluiu o curso de pósgraduação em economia na USP e, em 1969, mudou-se 
para os Estados Unidos, onde fez pós-graduação $e$ mestrado em economia. Casou-se com um gaúcho e, quando voltou ao Brasil, no início da década de 1970, foi residir em Porto Alegre (o marido se tornou professor titular do Departamento de Economia da Universidade Federal do Rio Grande do Sul). A partir de 1974, começou a trabalhar como consultora de empresas e, dois anos mais tarde, especializou-se em estatística pela UFRGS. Em 1983, assumiu a coordenação do Curso de Pós-Graduação em Economia da UFRGS, função que exerceu até 1986, quando se tornou membro do conselho fiscal do Banco Meridional, em Porto Alegre. Em 1988, foi contratada como comentarista econômica pela Rede Brasil Sul de Comunicações (RBS), afiliada à Rede Globo de Televisão. Entre 1989 e 1990, foi vice-diretora da Faculdade de Economia da UFRGS e, ainda neste último ano, filiou-se ao Partido da Social Democracia Brasileira (PSDB). Foi diretora da Faculdade de Economia de 1991 a 1992, deixou a RBS em abril deste último ano. A carreira pública se iniciou em 1993, com o cargo de ministra-chefe da Secretaria de Planejamento, Orçamento e Coordenação no governo de Itamar Franco (1992-1994), por indicação do Ministro da Fazenda, Paulo Haddad, seu amigo desde 1970 e interino na pasta do Planejamento. No mesmo ano, integrou os conselhos administrativos do Banco Meridional e do Banco Nacional do Desenvolvimento Econômico e Social (BNDES), além de exercer a função de primeira vicepresidente do diretório regional do PSDB gaúcho. Em 1994, tornou-se a primeira-tesoureira do PSDB nacional e elegeuse deputada federal pelo RS. Reeleita em 1998, em maio de 1999 foi nomeada diretora de estudos e pesquisas do Instituto Teotônio Vilela. Não teve êxito no pleito para a prefeitura de Porto Alegre (2000), elegendo-se novamente deputada federal (2002). Em 2006, conquistou o governo do estado do RS. Não sendo reeleita em 2010, em 2012 voltou a trabalhar como jornalista, dessa vez na Rede Pampa, e como colunista no Jornal Gente, da Rádio Bandeirantes de Porto Alegre. A publicação dessa agente é preponderantemente voltada para questões econômicas 
interseccionadas com as questões políticas (Principal fonte:

Dicionário Histórico e Biográfico Brasileiro).

Um aspecto interessante presente em quase todas as biografias, já referido por Barreira (2006), diz respeito à ênfase na dimensão do pioneirismo que enfatizam e que é decorrente justamente de um processo gradativo de afirmação de representantes mulheres $e$ da sua persistente raridade. As justificativas suscitadas (por intelectuais e militantes) para $\mathrm{o}$ limitado (e geralmente lamentado) número de mulheres na política institucional e partidária formam o repositório de predicados sobrelevados por lideranças que conseguiram transpor tais obstáculos, por exemplo, compatibilizar a "vida pessoal" com a "vida pública", enfrentar preconceitos de gênero, ter capacidade (em vários sentidos) de interpelação, guiar-se por sentidos de missão, abnegação, entre outros. $\mathrm{O}$ que também garante o peso de distinção do vanguardismo nas biografias: "única representante da bancada", "primeira senadora paulista", "primeira a governar o Rio Grande do Sul", "primeira a dirigir a faculdade de Ciências Econômicas da UFRGS", "primeira a ocupar uma vaga no Senado Federal", "primeira mulher negra a ocupar uma vaga no Senado", "primeira mulher pernambucana a ocupar uma cadeira do plenário da Câmara Federal", entre outros.

\section{Considerações finais}

Há inúmeras diferenças instauradas nas relações de qualificação e detração entre os sexos, determinando como "homens" $e$ "mulheres" devem ser identificados e se identificam enquanto tais, prescrevendo suas respectivas disposições e papeis. $\mathrm{Na}$ transposição das barreiras que separam "profanos" $e$ "profissionais" (no sentido weberiano), as mulheres são "mulheres na política" e, apesar de raras, acumulam e redefinem identificações que comportam o duplo papel político. Como nas dimensões sistematizadas por Alessandro Pizzorno (1991; 1986), autorizam-se a produzir identidades coletivas (a partir de 
associações, movimentos, partidos e escritos...) criando símbolos de reconhecimento, de solidariedade, de mobilização (dimensão simbólica); e conquistam a autoridade tanto para tomar decisões que envolvem a utilização de determinadas estruturas institucionais, como para agilizar estratégias que produzem adesões (leis, direitos etc.).

A raridade dos perfis aqui analisados está fundada em notoriedades advindas da capacidade de mobilizar atributos acumulados em domínios diversos (inscrições em esferas da produção cultural, da exposição midiática, do magistério, entre outras). Concentrando multinotabilidades ${ }^{9}$ desde o momento das suas entradas na política, elas passam a desfrutar de bases institucionais propiciadas por partidos políticos (vagas em nominatas, estruturas de campanha e aportes financeiros). Com a proeminência que adquirem em instâncias de poder institucionalizadas, como no legislativo e no executivo, podem capitalizar mais fortemente tal reputação como trunfo de luta política na concorrência com seus pares (homens e mulheres). Galgaram posições ainda mais dominantes com a paulatina modificação na balança de poder entre os sexos e suas repercussões em âmbitos políticos, econômicos e culturais e, talvez em especial, com a adoção da regra de cotas para mulheres nas listas dos partidos brasileiros desde a década de 1990, já explorada na literatura.

Cabe salientar que a escalada de cargos (secretarias, ministérios, comissões etc.) e as atribuições que detiveram (portavozes de bandeiras de lutas em universos privilegiados) parecem solidamente associadas à demonstração de saberes que se cristalizaram em exposições personalizadas de competências (via magistério, fundações, mídias e produções escritas), autorizandoas às investiduras em postos de comando político. Contudo, os meios utilizados para transpor as barreiras que se antepõem à

\footnotetext{
9 Sobre a noção de multinotabilidades para informar os vários e indissociáveis reconhecimentos acumulados por políticos com trajetórias de investimentos intelectuais e políticos, ver Reis \& Grill (2013).
} 
participação no âmbito do espaço do poder são simultaneamente fatores, para a maior parte dos casos, de restrição do leque de lugares, causas e linguagens que estão aptas a ocupar, defender ou pronunciar. Como num jogo de ganhos e perdas, produzem efeitos de subversão - interferências que provocam redefinições de formas de agir e de pensar o mundo social e o mundo político sem, paradoxalmente, conseguir fugir aos constrangimentos do jogo político e do jogo de gênero.

Como pista, aponta-se que o conjunto de posições $e$ posicionamentos assumidos pelas parlamentares permite que alinhem uma base triádica de notabilidades: formulação, transmissão e delegação. Quer dizer, a intervenção no espaço público é tributária da acumulação, da combinação e da mobilização de trunfos advindos da capacidade de formação, de interpelação e de transmissão fundadas nas atuações como professoras, comunicadoras, militantes e escritoras. Isso não está separado da "arte de representar", do fetichismo da delegação política (Bourdieu, 2004), que vai além da aptidão para realizar obras ou para falar em nome de determinadas causas ou categorias, mas está fundado no reconhecimento da capacidade de produzir seus fundamentos teóricos e reflexivos, e ainda sustentá-los e transmiti-los como problemas legítimos em espaços de consagração cultural e política.

\section{Referências bibliográficas}

ACHIN, Catherine. Démocratisation du personnel politique et parité: un premier bilan. Mouvements n ${ }^{\circ} 18$, Paris, La Découvert, nov-déc 2001, pp.57-61.

ARAÚJO, Clara. Gênero e acesso ao poder legislativo no Brasil: as cotas entre as instituições e a cultura. Revista Brasileira de Ciência Política, $\mathrm{n}^{\circ}$ 2, Brasília, UNB/Instituto de Ciência Política, julho/dezembro 2009, pp.23-59.

ARAÚJO, Clara. Partidos políticos e gênero: mediações nas rotas de ingresso das mulheres na representação política. Revista de Sociologia e Política 24, Curitiba, jun. 2005, pp.193-215. 
AVELAR, Lúcia. Mulheres na elite política brasileira. São Paulo, Fundação Konrad Adenauer/Editora da UNESP, 2001.

BARREIRA, Irlys. Práticas parlamentares, habitus e performances no campo da política: a participação de mulheres no Congresso Nacional. Comunicação no $30^{\circ}$ Encontro Anual da ANPOCS, Caxambu, 2006.

BAudelot, Christian, EstaBlet, Roger. Quoi de neuf chez les filles? Entre stéréotypes et libertés. Paris, Nathan, 2007.

BOURDIEU, Pierre. A delegação e o fetichismo político. In: BouRDIEU, Pierre. Coisas ditas. São Paulo, Brasiliense, 2004, pp.188-206.

BouRdieU, Pierre. O Ponto de Vista do Autor. Algumas propriedades Gerais dos Campos de Produção Cultural. In: BouRdiEU, Pierre. As Regras da Arte. São Paulo, Companhia das Letras, 1996, pp.243-316.

BOURDIEU, Pierre A representação política. Elementos para uma teoria do campo político. In: BouRdIEU, Pierre. O Poder simbólico, Lisboa, Difel, 1989, pp.163-207.

CHARLE, Christophe. Naissance des 'intellectuels' (1880-1900). Paris, Éditions de minuit, 1990.

Collovald, Annie. La République du militant: recrutement et filières de la carrière des députés, In. BIMBAUM, Pierre (dir.). Les élites socialistes au pouvoir. Paris, PUF, 1985, pp.11-52.

CORADINI, Odaci Luiz e REIS, Eliana T. dos. Transações culturais, intelectuais e as ciências sociais. Revista Pós Ciências Sociais, vol. 9, n 17, São Luís, EDUFMA, 2012, pp.09-17.

DOLAN, Kathleen. Voting for Women: How the Public Evaluates Women Candidates. Boulder, Westview Press, 2004.

ELIAS, Norbert. Introdução à Sociologia. Lisboa, Edições 70, 1999.

GAXIE, Daniel. La démocratie représentative. Paris, Montchrestien, 1992.

GRILL, Igor G. \& Reis, Eliana T. dos. O que escrever quer dizer na política? Carreiras políticas e gêneros de produção escrita. Revista Pós de Ciências Sociais, vol. 09, n¹7, São Luís, EDUFMA, 2012, pp.101-122.

GRILL, Igor G. Especialização política: bases sociais, profissionalização e configurações de apoios. In: SEIDL, E.; GRILL, I.G. (orgs.). As Ciências 
Sociais e os Espaços da Política no Brasil. Rio de Janeiro, Editora da FGV, 2013, pp.227-278.

Grossi, Mirian P. e Miguel, Sônia M. Transformando a diferença: as mulheres na política. Estudos Feministas, vol.9, n¹, Florianópolis-SC, 2001, pp.211-221.

Guionnet, Christine e NEVEU, Érik. Féminin/Masculin. Sociologie du genre. Paris, Armand Colin (Collection U), 2004.

LAGRAVE, Rose Marie. Recherches féministes ou recherches sur les femmes. Actes de la recherche en sciences sociales (83), Paris, Le Seuil, 1990, pp.27-39.

LE BART, Christian. L'écriture comme modalité déxercice du métier politique. Revue Française de Science Poltique, vol. 48, Paris, Presses de Sciences Po, 1998, pp.76-96.

LEVEQUE, Sandrine et DULONG, Delphine. Une ressource contingente. Les conditions de reconversion du genre en ressource politique. Politix, vol. 14, n 60, Paris, De Boeck Supérieur, Année 2002, pp.81-111.

LOUREIRO, Maria Rita. Economistas e elites dirigentes no Brasil. Revista Brasileira de Ciências Sociais, $\mathrm{n}^{\circ}$ 20, ano 7, São Paulo, Anpocs, outubro de 1992, pp.47-68.

MARENCO DOS SANTOS, André. Não se fazem mais oligarquias como antigamente. Tese de Doutorado, PPGCP/UFRGS, Porto Alegre, 2000.

MEDVETZ, Tom. Hybrid intellectuals: toward a theory of think tanks and public policy experts in the United States. Paper Social Sciences. December, $1990 . \quad$ Disponível em: $<$ http://www.socialsciences.cornell.edu/0609/Medvetz.html $>$.

MiCELI, Sérgio. Intelectuais e Classe Dirigente no Brasil (1920-1945). Rio de Janeiro, Difel/Difusão Editorial S.A., 1979.

PECAUT, Daniel. Os intelectuais e a política no Brasil, entre o povo e a nação. São Paulo, Ática, 1990.

PERROT, Michelle. Escrever uma história das mulheres. Relato de uma experiência. Cadernos Pagu (4), Campinas-SP, Núcleo de Estudos de Gênero-Pagu/Unicamp, 1995, pp.9-28.

PINTO, Céli Regina J. Feminismo, História e poder. Revista de Sociologia e Política vol. 18, Paraná, UFPR, 2010, pp.15-23. 
PINTO, Céli Regina J. Paradoxos da participação política das mulheres no Brasil. Revista USP n 49, São Paulo, março/maio 2001, pp.98-112.

Pizzorno, Alessandro. Algum tipo diferente de diferença: uma crítica das teorias da escolha racional. In: FOXLEY, A. et alli. Desenvolvimento $e$ Política. São Paulo, Vértice, 1988, pp.366-386.

PIZZORNO, Alessandro. Sur la rationalité du choix démocratique. In: BIRNBAUM, Pierre e LECA, Jean (dir). Sur l'individualisme. Paris, FNSP, 1986, pp.364-369.

REIS, Eliana T. dos \& Grill, Igor G. "Arte de escrever", "Vocação para representar": trajetórias e produção intelectual de políticos brasileiros. Paper apresentado no XVI Congresso brasileiro de Sociologia, UFBA, Salvador, 10-13 setembro de 2013.

SCOTT, Joan Wallach. Gênero: uma categoria útil de análise histórica. Educação \& Realidade vol. 20, n 2, Porto Alegre, jul./dez. 1995, pp.71-99.

SigAL, Silvia. Intelectuais, Cultura e Política na Argentina. Revista Pós Ciências Sociais vol.9, n¹7, São Luís, EDUFMA, 2012, pp.51-66.

SiMIONI, Ana Paula Cavalcanti. Profissão artista: pintoras e escultoras acadêmicas brasileiras. São Paulo, Editora da Universidade de São Paulo/Fapesp, 2008.

SOUZA LOBO, Elisabeth. O gênero da representação: representação política no Brasil (1980-1990). Revista Brasileira Ciências Sociais ${ }^{\circ}$ 17, São Paulo, Anpocs, 1991, pp.7-14.

Sow, Marilene Mendes. A participação feminina na construção de um parlamento democrático. E-Legis n ${ }^{\circ} 05$, Brasília, $2^{\circ}$ semestre de 2010, pp.79-94.

Velloso, Mônica Pimenta. Os intelectuais e a política cultural do Estado Novo. Rio de Janeiro, FGV/CPDOC, 1987. 